\title{
Discussion
}

\section{An Uncommon Complication of Secondary Augmentation Mammoplasty}

This is an interesting report of a very rare complication after augmentation mammoplasty. A literature review shows only one previous report of two patients with galactoceles after breast augmentation [2]. Although plastic surgeons may have heard of galactoceles after augmentation mammoplasty, most probably have not seen them.

Although uncommon, galactoceles usually occur in lactating women, but there are several reports of galactoceles in male infants [3]. The common pathophysiology is believed to be plugging of the lacteal ducts in the presence of milk production, leading to galactocele formation. The principle diagnostic tools are ultrasound and aspiration of the fluid collection. Sometimes aspiration alone may treat a galactocele, and direct ductal probing also is shown to be an effective treatment [1]. If there is an associated infection, antibiotics are indicated. Bromocriptine, an ergot alkaloid that inhibits the release of prolactin, the hormone responsible for milk production, also can be used to treat galactoceles.

In their article, the authors describe a patient with a history of mastitis and problems with lactation. They also report that they encountered a $1-\mathrm{cm}$ cyst during her first operation. Certainly, latent and colonized bacteria could have occupied the lacteal ducts or cyst, increasing the risk of an infection with the first set of implants. This underscores the importance of a thorough obstetric and lactation history particularly a history of mastitis, when breast augmentation, is considered.

The authors treated the reported patient with antibiotics and close observation. In the absence of milky drainage, ultrasound of the breast can identify certain features unique to galactoceles [4]. If aspiration is considered for diagnosis or treatment in the presence of an implant, ultrasound also would serve to minimize the risk of damage to the implant.
The question arises whether we should consider the periaereolar approach for women who plan to have children and breast-feed, or for those who have a history of mastitis, lactation related or otherwise. The reported patient underwent three procedures through the periaereolar incision leading to more trauma and scarring of the breast and lacteal ducts. We agree with the authors that scarring around the lacteals with blockage likely caused the galactocele formation. Avoidance of dissection through breast tissue and the ductal system offers a theoretical advantage in avoiding trauma and scarring to the ductal system as well as exposure to latent and colonized bacteria, and should be considered in such cases.

Again, we thank the authors for bringing this rare and unusual problem to our attention.

Farzad R. Nahai M.D.

Foad Nahai M.D.

Paces Plastic Surgery

3200 Downwood Circle Suite 640

Atlanta, Georgia 30327

email: Nahaimd@aol.com

\section{References}

1. Auvichayapat P, Auvichayapat N, et al.: A controlled trial of a new treatment for galactocele. J Med Assoc Thai 86:257-261, 2003

2. Deloach ED, Lord SA, Ruf LE: Unilateral galactocele following augmentation mammoplasty. Ann Plast Surg 33:68-71, 1994

3. Orbist P, Schabegger A, Brunhuber T, Schafer G, Kreczy A: Galactocele in a young male patient. Plast Recon Surg 112:186-188, 2003

4. Sawhey S, Petkovska L, Ramadan S, Al-Muhtaseb S, Jain R, Sheikh M: Sonographic appearances of galactoceles. J Clin Ultrasound 30:18-22, 2002 